\title{
Investigation of effects of varying model inputs on mercury deposition estimates in the Southwest US
}

\author{
T. Myers ${ }^{1}$, R. D. Atkinson ${ }^{2}$, O. R. Bullock Jr. ${ }^{3}$, and J. O. Bash ${ }^{3}$ \\ ${ }^{1}$ ICF International, 101 Lucas Valley Rd., San Rafael, CA 94903, USA \\ ${ }^{2}$ Office of Water, US Environmental Protection Agency, Washington, DC, USA \\ ${ }^{3}$ National Exposure Research Laboratory, US Environmental Protection Agency, Research Triangle Park, NC, USA \\ Correspondence to: T. Myers (thomas.myers@icfi.com)
}

Received: 6 March 2012 - Published in Atmos. Chem. Phys. Discuss.: 20 April 2012

Revised: 10 December 2012 - Accepted: 28 December 2012 - Published: 23 January 2013

\begin{abstract}
The Community Multiscale Air Quality (CMAQ) model version 4.7.1 was used to simulate mercury wet and dry deposition for a domain covering the continental United States (US). The simulations used MM5-derived meteorological input fields and the US Environmental Protection Agency (EPA) Clear Air Mercury Rule (CAMR) emissions inventory. Using sensitivity simulations with different boundary conditions and tracer simulations, this investigation focuses on the contributions of boundary concentrations to deposited mercury in the Southwest (SW) US. Concentrations of oxidized mercury species along the boundaries of the domain, in particular the upper layers of the domain, can make significant contributions to the simulated wet and dry deposition of mercury in the SW US. In order to better understand the contributions of boundary conditions to deposition, inert tracer simulations were conducted to quantify the relative amount of an atmospheric constituent transported across the boundaries of the domain at various altitudes and to quantify the amount that reaches and potentially deposits to the land surface in the SW US. Simulations using alternate sets of boundary concentrations, including estimates from global models (Goddard Earth Observing System-Chem (GEOSChem) and the Global/Regional Atmospheric Heavy Metals (GRAHM) model), and alternate meteorological input fields (for different years) are analyzed in this paper. CMAQ dry deposition in the SW US is sensitive to differences in the atmospheric dynamics and atmospheric mercury chemistry parameterizations between the global models used for boundary conditions.
\end{abstract}

\section{Introduction}

Regional scale simulations of mercury deposition must rely on boundary concentrations to account for fluxes of species, in particular the various mercury species, into the modeling domain from the remainder of the globe. In the North American Mercury Model Intercomparison Study (NAMMIS) Bullock Jr. et al. (2008) found that the mercury deposition simulated by regional scale models depends strongly on the initial and boundary concentrations of mercury compounds used for the regional scale simulations. Pongprueksa et al. (2008) found that the influence of the initial conditions was much weaker than the influence of boundary concentrations. Therefore, in order to interpret the results from regional scale simulations of mercury deposition, it is important to understand the influence that the boundary concentrations have on the simulated mercury deposition.

In this study, the results obtained in the NAMMIS study are expanded by considering, in addition to the effect of using alternate boundary concentrations, the effect of several other factors on simulated mercury deposition. Specifically, use of meteorological inputs for a different year; use of an alternative global model as a source of boundary concentrations for the regional scale simulations; changes in the high altitude boundary concentrations; and increased vertical resolution in the regional scale modeling domain are examined. In addition, tracer simulations are used to clarify how the simulated mercury species are transported from the boundary to areas in the domain that are impacted by the boundary concentrations. We use a $36 \mathrm{~km}$ resolution regional scale grid covering most of North America, but some of the analyses 
are focused on locations in the Southwest (SW) US where CMAQ model simulations showed high levels of total $\mathrm{Hg}$ dry deposition compared to other models considered in the NAMMIS (Bullock Jr. et al., 2008).

\section{Background on simulations}

The Community Multiscale Air Quality (CMAQ) model version 4.7.1 (Foley et al., 2010) was used to simulate mercury wet and dry deposition for a domain covering the contiguous US and parts of Mexico and Canada. Mercury oxidation reactions in CMAQ 4.7.1 include reaction of $\mathrm{Hg}^{0}$ with ozone, peroxide and the $\mathrm{OH}$ radical in gas phase. In aqueous phase, reaction of $\mathrm{Hg}^{0}$ with ozone, chlorine, and $\mathrm{OH}$ are included. Various reduction reactions are included in the aqueous phase chemistry, including $\mathrm{Hg}^{2+}$ reaction with sulfite and with $\mathrm{HO}_{2}$. More detailed documentation of the CMAQ mercury mechanism can be found in Bullock Jr. and Brehme (2002) and the technical support document for the Clean Air Mercury Rule (EPA, 2005a). The simulations in this study were made with CMAQ 4.7.1 without the elemental $\mathrm{Hg}-\mathrm{NO}_{3}$ reaction. Sommar et al. (1997) reported an oxidation rate constant for $\mathrm{Hg}^{0}$ with $\mathrm{NO}_{3}$ radicals and this was implemented in CMAQ 4.7. This oxidation mechanism can have an impact on atmospheric mercury (Subir et al., 2011). However, the rate constant reported by Sommar et al. (1997) was not statistically different from 0 and the assumed products are thermodynamically unfavorable (Hynes et al., 2009). The inclusion of this reaction mechanism in CMAQ 4.7 was found to overestimate the modeled wet deposition when compared to MDN observations (116\% normalized mean bias in January and February 2002 simulations and $11 \%$ normalized mean bias (NMB) in July and August 2002 simulations) and found to result in ambient low, sub $1 \mathrm{ng} \mathrm{m}^{-3} \mathrm{Hg}^{0}$ concentrations, in hemispheric CMAQ simulations. The removal of $\mathrm{Hg}^{0}$ oxidation by the $\mathrm{NO}_{3}$ radical reduced the January and February wet deposition bias (31\% NMB) and introduced a negative bias in the July and August 2002 simulations ( $-23 \%$ NMB but decreased the normalized mean error from $44 \%$ to $39 \%$ ). CMAQ with v4.7.1 with this change to the chemical mechanism was found to simulate wet deposition well when compared to MDN observations and CAMx simulations (Baker and Bash, 2012). This GEM oxidation pathway was removed in CMAQ 5.0. Total dry deposition of mercury presented here includes only deposition of divalent gas mercury and particulate mercury. The deposition of elemental mercury simulated by CMAQ is not included in the analyses. The bidirectional deposition algorithm for elemental mercury in CMAQ (Bash, 2010) was not used in this study, and it is therefore assumed that deposition of elemental mercury would be roughly offset by subsequent evasion of elemental mercury. This study therefore focusses on the deposition of divalent forms of mercury which would contribute to a net increase in the mercury loadings of the affected land areas.
All simulations reported here used meteorological input files derived from the Fifth Generation Mesoscale Model (MM5; Grell et al., 1994) simulations. The 2001 simulations used meteorological files and emissions files from the NAMMIS. The emissions files were developed from the US EPA Clean Air Mercury Rule (CAMR) emissions inventory (EPA, 2005b), and these emissions files were also used for the 2005 simulations. In addition, the MM5 model outputs used to prepare the 2001 meteorological inputs were re-processed using the Meteorology-Chemistry Interface Processor (MCIP) v3.4.1 (Otte et al., 2005) to prepare CMAQ input files with both 14 vertical layers and 34 vertical layers. The 34-layer data files were used only for the tracer simulations reported in Sect. 7. CMAQ ready meteorological files for 2005 with 14 vertical layers were also derived from MM5 outputs. These 2005 files were acquired from EPA and had been used in past EPA studies (EPA, 2009).

The 14-layer vertical grid configuration used for the CMAQ simulations reported here is the same as was used for the CMAQ simulations reported in NAMMIS: a sigmapressure based vertical coordinate system with model top at $10 \mathrm{kPa}$. The 34-layer grid configuration used in simulations in Sect. 7 used the same model top with additional sigma layers. The correspondence of layers for the 14 and 34 layer grid systems is shown in Table 1.

The 2002 CMAQ simulation used 14-layer meteorological files derived from MM5 simulations and emissions from the 2002 National Emissions Inventory (http://www.epa.gov/ttn/ chief/net/critsummary.html).

Boundary and initial conditions for mercury species derived from GEOS-Chem (Bey et al., 2001) and the Global/Regional Atmospheric Heavy Metals (GRAHM) (Dastoor and Larocque, 2004; Ariya et al., 2004) are those developed by participants in NAMMIS: GEOS-Chem by Harvard University (Selin et al., 2007), and GRAHM by Environment Canada. Initial and boundary concentrations of all species other than mercury were derived from the NAMMIS GEOS-Chem simulation and were the same for all simulations reported here.

Concentrations of oxidized mercury species along the boundaries of the domain, in particular the upper layers of the domain, can make significant contributions to the simulated wet and dry deposition of mercury in the SW US. In order to better understand the contributions of boundary conditions to deposition, inert tracer simulations were conducted to quantify the relative amount of atmospheric constituents transported across the boundaries of the domain at various altitudes and to quantify the amount of those traces that reach and potentially deposit to the land surface in the SW US. Using sensitivity simulations and tracer simulations, this investigation focuses on the contributions of boundary concentrations to deposited mercury in the SW US.

Simulations were initiated on 21 June and were run through 31 July of 2001 and 2005. Deposition totals are for 1 July through 31 July. Additional simulations were run for 
Table 1. Sigma-p layer definitions for 14-layer and 34-layer CMAQ simulations.

\begin{tabular}{|c|c|c|c|}
\hline $\begin{array}{l}\text { Layer No. in } \\
\text { 14-layer grid }\end{array}$ & $\begin{array}{l}\text { Layer No. in } \\
\text { 34-layer grid }\end{array}$ & $\begin{array}{l}\text { Sigma-p at } \\
\text { layer top }\end{array}$ & $\begin{array}{r}\text { Approximate height } \\
\text { of layer top above } \\
\text { ground }(\mathrm{m})^{*}\end{array}$ \\
\hline 1 & 1 & 0.995 & 36 \\
\hline \multirow[t]{2}{*}{2} & 2 & 0.99 & 72 \\
\hline & 3 & 0.985 & 107 \\
\hline \multirow[t]{2}{*}{3} & 4 & 0.98 & 144 \\
\hline & 5 & 0.97 & 216 \\
\hline \multirow[t]{2}{*}{4} & 6 & 0.96 & 289 \\
\hline & 7 & 0.95 & 363 \\
\hline \multirow[t]{3}{*}{5} & 8 & 0.94 & 437 \\
\hline & 9 & 0.93 & 512 \\
\hline & 10 & 0.92 & 587 \\
\hline \multirow[t]{3}{*}{6} & 11 & 0.91 & 663 \\
\hline & 12 & 0.9 & 740 \\
\hline & 13 & 0.88 & 895 \\
\hline \multirow[t]{3}{*}{7} & 14 & 0.86 & 1052 \\
\hline & 15 & 0.84 & 1213 \\
\hline & 16 & 0.82 & 1375 \\
\hline \multirow[t]{2}{*}{8} & 17 & 0.8 & 1541 \\
\hline & 18 & 0.77 & 1795 \\
\hline \multirow[t]{2}{*}{9} & 19 & 0.74 & 2057 \\
\hline & 20 & 0.7 & 2417 \\
\hline \multirow[t]{2}{*}{10} & 21 & 0.65 & 2887 \\
\hline & 22 & 0.6 & 3383 \\
\hline \multirow[t]{3}{*}{11} & 23 & 0.55 & 3907 \\
\hline & 24 & 0.5 & 4464 \\
\hline & 25 & 0.45 & 5057 \\
\hline \multirow[t]{4}{*}{12} & 26 & 0.4 & 5694 \\
\hline & 27 & 0.35 & 6380 \\
\hline & 28 & 0.3 & 7126 \\
\hline & 29 & 0.25 & 7946 \\
\hline \multirow[t]{4}{*}{13} & 30 & 0.2 & 8855 \\
\hline & 31 & 0.15 & 9881 \\
\hline & 32 & 0.1 & 11063 \\
\hline & 33 & 0.05 & 12464 \\
\hline 14 & 34 & 0 & 14205 \\
\hline
\end{tabular}

* Height is for cell 74, 56 located in the central United States which is at an elevation of approximately $444 \mathrm{~m}$ above sea level. Heights of cells will vary throughout the domain depending on the height of the underlying terrain.

January-February and July-August 2002 that used boundary concentrations based on a CMAQ northern-hemispheric simulation.

In the sections below, simulation results for the following cases will be discussed: use of alternative sets of boundary concentrations for mercury species; effect of altering boundary concentrations of mercury at high altitudes; tracers showing the contribution of boundary regions to surface concentrations; effect of alternate meteorology on estimated deposition (using 2001 vs. 2005 meteorological data); and effect of higher vertical resolution on tracer results.
Table 2. Definition of Statistical Performance Metrics for $\mathrm{Hg}$ Deposition*.

\begin{tabular}{|c|c|}
\hline Performance Metric & Equation \\
\hline Mean Bias $\left(\mathrm{ng} \mathrm{m}^{-2}\right)$ & $\mathrm{MB}=\frac{1}{N} \sum_{i=1}^{N}\left(D_{\mathrm{m}}-D_{\mathrm{o}}\right)$ \\
\hline Mean Error $\left(\mathrm{ng} \mathrm{m}^{-2}\right)$ & $\mathrm{ME}=\frac{1}{N} \sum_{i=1}^{N}\left|D_{\mathrm{m}}-D_{\mathrm{o}}\right|$ \\
\hline $\begin{array}{l}\text { Normalized Mean Bias } \\
(-1 \text { to }+\infty) \\
\text { Normalized Mean Error } \\
(0 \text { to }+\infty)\end{array}$ & $\begin{array}{l}\mathrm{NMB}=\frac{\sum_{i=1}^{N}\left(D_{\mathrm{m}}-D_{\mathrm{o}}\right)}{\sum_{i=1}^{N} D_{\mathrm{o}}} \\
\mathrm{NME}=\frac{\sum_{i=1}^{N}\left|D_{\mathrm{m}}-D_{\mathrm{o}}\right|}{\sum_{i=1}^{N} D_{\mathrm{o}}}\end{array}$ \\
\hline $\begin{array}{l}\text { Mean Fractional Error } \\
(0 \text { to }+2)\end{array}$ & $\mathrm{MFE}=\frac{1}{N} \sum_{i=1}^{N} \frac{\left|D_{\mathrm{m}}-D_{\mathrm{o}}\right|}{\left(\frac{D_{\mathrm{o}}+D_{\mathrm{m}}}{2}\right)}$ \\
\hline
\end{tabular}

* $D_{\mathrm{m}}$ is model value and $D_{\mathrm{o}}$ is observed value.

Statistical performance measures similar to those used in NAMMIS (Bullock Jr. et al., 2009) are presented for each of the simulated periods presented in this paper. The statistical comparison evaluates the simulated wet deposition, either monthly or bimonthly totals depending on the simulation period, against the Mercury Deposition Network (MDN) (Vermette et al., 1995) observed wet deposition totals for the same period. In addition to mean value, standard deviation $(\sigma)$, and the coefficient of determination $\left(r^{2}\right)$, the statistical measures shown in Table 2 are presented. No evaluation of dry deposition is included due to the lack of an adequate database of observed dry deposition for the simulated periods. Additional information on model performance for the full annual simulations from which our monthly simulations are derived can be found in other references. For instance, model performance for the 2001 meteorology was evaluated in the NAMMIS paper (Bullock Jr. et al., 2009). Model performance summaries for mercury were also presented elsewhere for an annual 2005 simulation using the same model options as the 2002 simulations presented here (Baker and Bash, 2012).

\section{Alternate sets of boundary concentrations}

\subsection{GEOS-Chem vs. GRAHM boundary conditions}

The effect of global transport of mercury is embodied in the boundary concentrations used for a regional simulation. The choice of these boundary concentrations can have a significant effect of the simulated estimates of deposition of atmospheric pollutants (Schere et al., 2011). This comparison 
Table 3. Observed and Simulated Mean and Standard Deviation for Monthly (or Bi-Monthly) Hg Wet Deposition at All Monitors and Model Correlations to All Observations of Monthly (or Bi-Monthly) Hg Wet Deposition.

\begin{tabular}{|c|c|c|c|c|c|c|c|c|c|c|c|c|}
\hline & \multicolumn{3}{|c|}{ July 2001} & \multicolumn{3}{|c|}{ July 2005} & \multicolumn{3}{|c|}{ January-February 2002} & \multicolumn{3}{|c|}{ July-August 2002} \\
\hline & Obs. & $\begin{array}{l}\text { CMAQ } \\
\text { w/GEOS- } \\
\text { Chem BC }\end{array}$ & $\begin{array}{l}\text { CMAQ } \\
\text { w/GRAHM } \\
\text { BC }\end{array}$ & Obs. & $\begin{array}{l}\text { CMAQ } \\
\text { w/GEOS- } \\
\text { Chem BC }\end{array}$ & $\begin{array}{l}\text { CMAQ } \\
\text { w/GRAHM } \\
\text { BC }\end{array}$ & Obs. & $\begin{array}{l}\text { CMAQ } \\
\text { w/GEOS- } \\
\text { Chem BC }\end{array}$ & $\begin{array}{l}\text { CMAQ } \\
\text { w/Adj. } \\
\text { GEOS- } \\
\text { Chem BC }\end{array}$ & Obs. & $\begin{array}{l}\text { CMAQ w/ } \\
\text { GEOS-Chem } \\
\text { BC }\end{array}$ & $\begin{array}{l}\text { CMAQ w/ } \\
\text { Adj. GEOS- } \\
\text { Chem BC }\end{array}$ \\
\hline Mean $\left(\mathrm{ng} \mathrm{m}^{-2}\right)$ & 1063.7 & 895.9 & 998.1 & 1398.0 & 991.6 & 1095.6 & 764.8 & 1003.6 & 576.2 & 2111.4 & 1622.2 & 1124.0 \\
\hline$\sigma\left(\mathrm{ng} \mathrm{m}^{-2}\right)$ & 842.8 & 519.4 & 596.4 & 973.9 & 529.1 & 536.1 & 410.0 & 786.4 & 387.8 & 1531.1 & 1182.6 & 872.0 \\
\hline$r^{2}$ & & 0.245 & 0.354 & & 0.040 & 0.152 & & 0.520 & 0.584 & & 0.587 & 0.598 \\
\hline $\begin{array}{l}\text { Mean bias } \\
\left(\mathrm{ng} \mathrm{m}^{-2}\right)\end{array}$ & & -167.8 & -65.6 & & -406.4 & -302.3 & & 238.8 & -188.6 & & -489.2 & -987.4 \\
\hline $\begin{array}{l}\text { Mean error } \\
\left(\mathrm{ng} \mathrm{m}^{-2}\right)\end{array}$ & & 534.7 & 492.4 & & 747.8 & 663.6 & & 444.7 & 267.0 & & 834.0 & 1115.3 \\
\hline $\begin{array}{l}\text { Normalized } \\
\text { mean bias }\end{array}$ & & -0.16 & -0.06 & & -0.29 & -0.22 & & 0.31 & -0.25 & & -0.23 & -0.47 \\
\hline $\begin{array}{l}\text { Normalized } \\
\text { mean error }\end{array}$ & & 0.50 & 0.46 & & 0.53 & 0.47 & & 0.58 & 0.35 & & 0.39 & 0.53 \\
\hline $\begin{array}{l}\text { Mean fractional } \\
\text { error }\end{array}$ & & 0.58 & 0.55 & & 0.59 & 0.54 & & 0.58 & 0.57 & & 0.51 & 0.72 \\
\hline
\end{tabular}

examines simulated total dry deposition and simulated mercury total wet deposition using two different sets of boundary concentrations for mercury derived from the global models GEOS-Chem and GRAHM. These CMAQ simulations were run with 14 vertical layers. The vertical variation in the boundary concentrations is shown in Fig. 1.

Although the elemental mercury $\left(\mathrm{Hg}^{0}\right)$ concentrations derived from the GEOS-Chem results and from the GRAHM results are similar near the surface, the GEOS-Chem boundary conditions are more than double the GRAHM boundary conditions at altitudes above $12000 \mathrm{~m}$. At lower altitudes, the reactive gaseous mercury (RGM) boundary conditions derived from GEOS-Chem, at around $80 \mathrm{pg} \mathrm{m}^{-3}$, are higher than the boundary conditions derived from GRAHM (about $30 \mathrm{pg} \mathrm{m}^{-3}$ ). At altitudes above $10000 \mathrm{~m}$, the GEOS-Chem boundary conditions on the north boundary range from 200$600 \mathrm{pg} \mathrm{m}^{-3}$ while the GRAHM boundary conditions range from about $100-350 \mathrm{pg} \mathrm{m}^{-3}$. On the south boundary, however, the GEOS-Chem Boundary conditions reach a maximum of only roughly $100 \mathrm{pg} \mathrm{m}^{-3}$ at the top of the domain, while the GRAHM boundary conditions reach $400 \mathrm{pg} \mathrm{m}^{-3}$ at the top of the domain. The GRAHM and GEOS-Chem boundary conditions for RGM are for the most part within about $50 \%$ of each other at higher altitudes on the west and east boundaries, covering a range of concentrations from about $50 \mathrm{pg} \mathrm{m}^{-3}$ at $10000 \mathrm{~m}$ to roughly $300 \mathrm{pg} \mathrm{m}^{-3}$ at the top of the domain. Particle bound mercury $(\mathrm{PHg})$ is only about $1 \mathrm{pg} \mathrm{m}^{-3}$ in the GEOS-Chem derived boundary conditions compared to the GRAHM derived boundary conditions which have concentrations of about $25 \mathrm{pg} \mathrm{m}^{-3}$ up to $10000 \mathrm{~m}$ and $125 \mathrm{pg} \mathrm{m}^{-3}$ at the top of the domain. The final panel of Fig. 1 shows the sum of $\mathrm{Hg}^{2+}$ and $\mathrm{PHg}$ in order to compare the total divalent mercury present on the boundaries. In general, the total divalent mercury boundary condi- tions derived from the two global models are closer than the separate components. GEOS-Chem derived boundary conditions remain higher at low altitudes on the west boundary and lower at high altitudes on the south boundary.

Statistical performance measures for the July 2001 simulations using the GEOS-Chem and GRAHM derived boundary conditions are presented in Table 3. (For ease of reference, Table 3 includes performance measures for simulated wet deposition from the July 2001, July 2005, January-February 2002, and July-August 2002 simulations. The statistical performance for each of the other simulated periods will be discussed when those results are introduced.) Using either GEOS-Chem or GRAHM boundary conditions results in a mean wet deposition lower than observed, although the case using GRAHM is somewhat closer than the GEOS-Chem case. Other statistical measures also favor the GRAHM case, the most notable being an $r^{2}$ of 0.354 for the GRAHM case compared to 0.245 for the GEOS-Chem case and a normalized mean bias of -0.06 for the GRAHM case and -0.16 for the GEOS-Chem case. The reader is reminded that these statistics are based on sites spread throughout the United States and Canada. Data is not available to allow evaluation of performance of the differing boundary conditions for the specific area that is emphasized in this paper (the SW US). No site was operational in Arizona during the simulated period. The only available site in California reports zero deposition for July 2001. Some wet deposition is simulated at the California site rather than zero (due to differences in precipitation estimates used in the CMAQ simulations compared to observed precipitation), but comparison of the differing estimates using the alternate boundary conditions to the zero value cannot yield any useful information about which better represents actual conditions. 

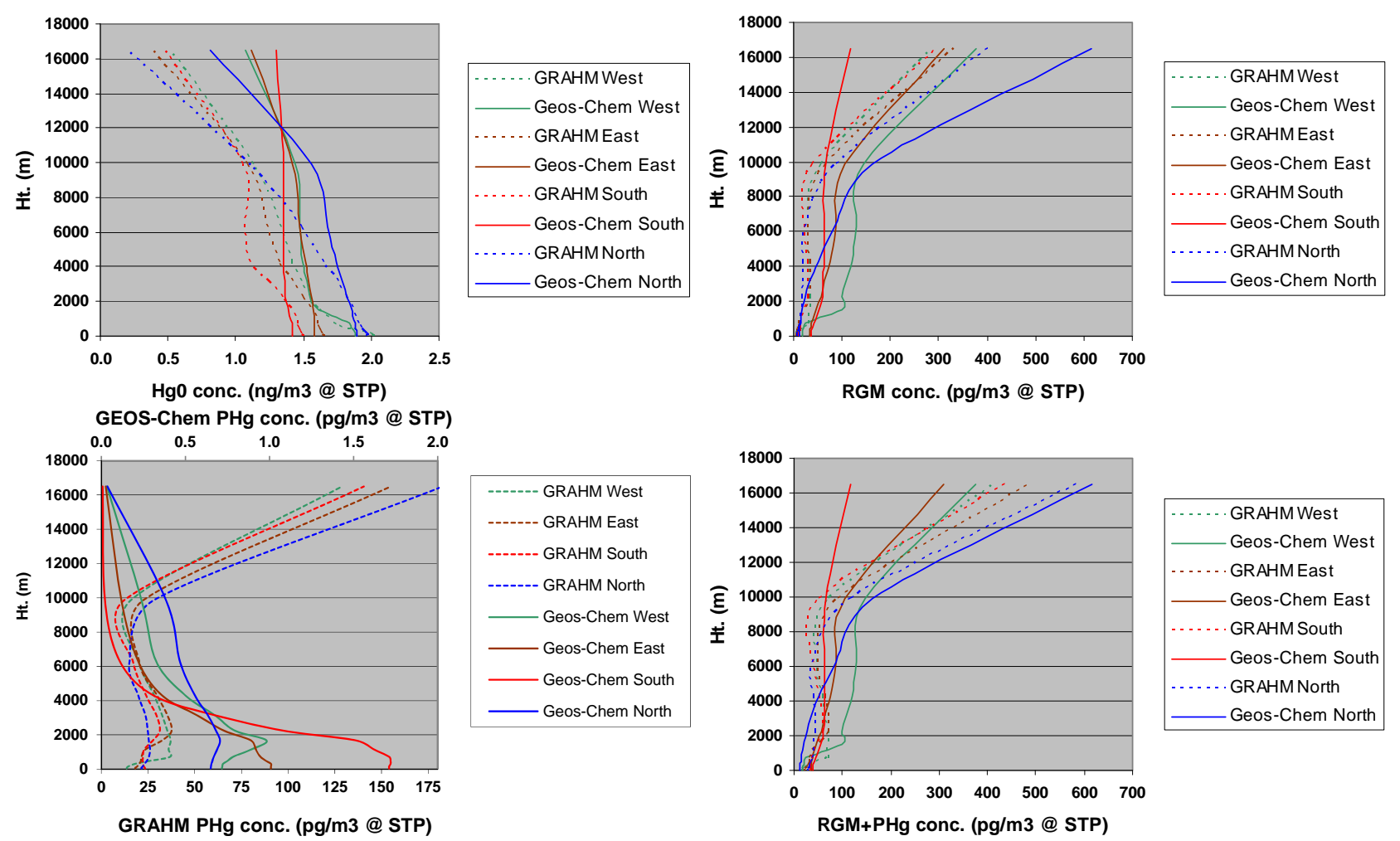

Fig. 1. Comparison of average vertical profiles of boundary conditions derived from the GEOS-Chem and GRAHM global models. (Note that different scales are used for GEOS-Chem and GRAHM PHg concentrations.)

July Total Hg Wet Dep $\left(\mu \mathrm{g} \mathrm{m}^{-2} \mathrm{month}^{-1}\right)$
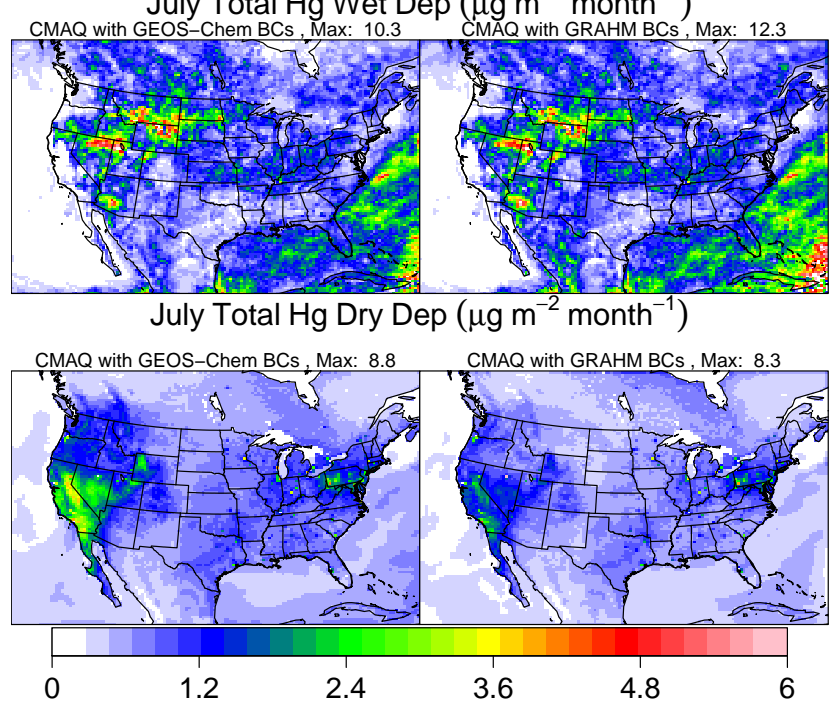

Fig. 2. CMAQ simulated mercury wet and dry deposition using boundary conditions derived from GEOS-Chem and GRAHM global models, with 2001 meteorological inputs. Circles on wet deposition plots indicate locations of Mercury Deposition Network wet deposition observations. Dry deposition includes only divalent forms of mercury.
Figure 2 demonstrates the substantially different estimates of mercury deposition that can result from the different boundary conditions. In particular, dry deposition in some parts of California and Nevada drops from $4 \mu \mathrm{g} \mathrm{m}^{-2}$ month $^{-1}$ using the GEOS-Chem boundary conditions to about $1.5 \mu \mathrm{g} \mathrm{m}^{-2}$ month $^{-1}$ using the GRAHM boundary conditions. Simulated wet deposition of mercury in some areas of Arizona is about $1.3 \mu \mathrm{g} \mathrm{m}^{-2}$ month $^{-1}$ using the GEOS-Chem boundary conditions but increases to $1.5 \mu \mathrm{g} \mathrm{m}^{-2}$ month $^{-1}$ using the GRAHM boundary conditions.

\subsection{Adjusted GEOS-Chem boundary conditions}

In this section, wet and dry mercury deposition simulated by CMAQ for January-February 2002 and July-August 2002 are compared using boundary conditions based on (a) 2002 GEOS-Chem global simulations and (b) the same GEOSChem simulations adjusted based on the results of a 2005 CMAQ hemispheric simulation to keep the spatial and temporal dynamics and non-mercury species constant in the boundary conditions between the simulations. The fraction of divalent oxidized mercury, $\mathrm{Hg}^{2+}$, to total gaseous mercury, $\left(\mathrm{Hg}^{0}+\mathrm{Hg}^{2+}\right)$, was compared between the April monthly mean 2005 CMAQ hemispheric run, the GEOSChem boundary conditions, and measurements taken aloft 


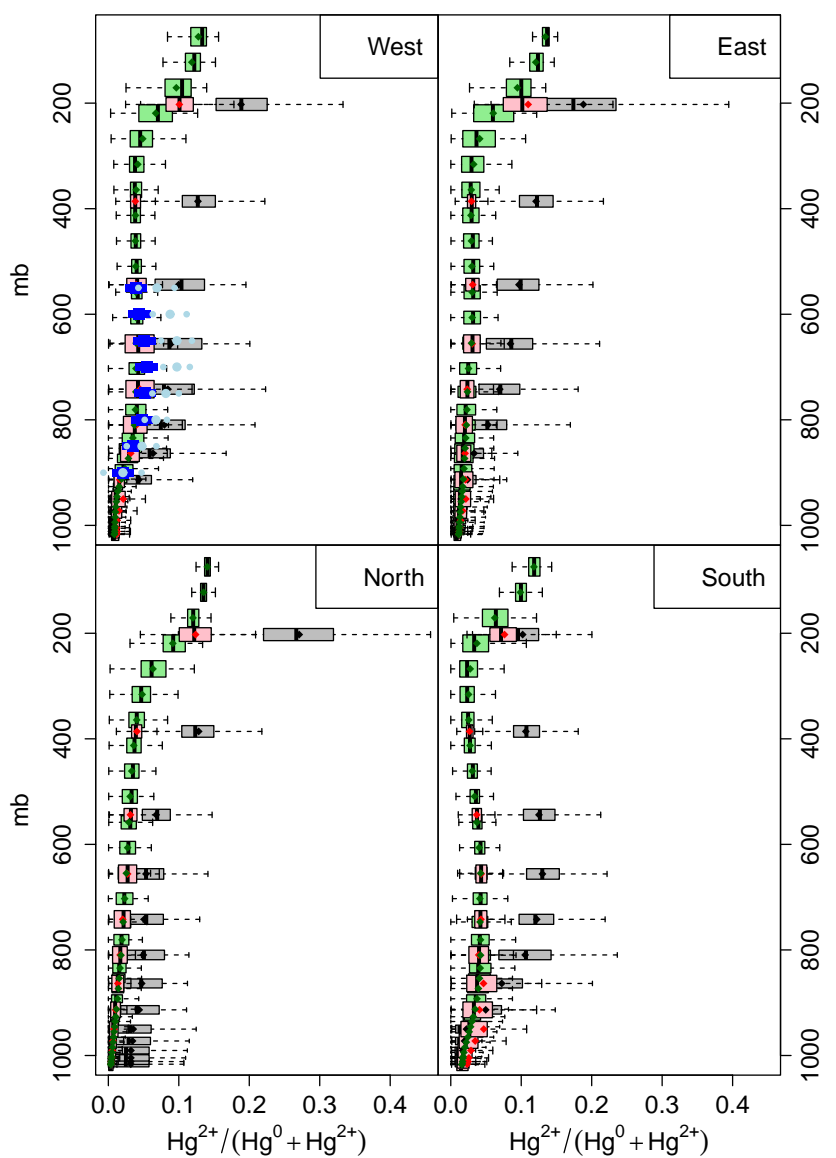

Fig. 3. April $\mathrm{Hg}^{2+} /\left(\mathrm{Hg}^{0}+\mathrm{Hg}^{2+}\right)$ GEOS Chem (gray), CMAQ Hemispheric (green), and adjusted GEOS Chem (pink) boundary conditions for the $\mathrm{Hg}$ regional $36 \mathrm{~km}$ CONUS CMAQ domain. University of Washington observations taken aloft using $\mathrm{KCl}$ denuders (dark blue) and difference techniques (light blue) are plotted on the top left panel.

from Schwarzendruber et al. (2009). GEOS-Chem boundary conditions were several factors larger than CMAQ boundary conditions above the $800 \mathrm{mb}$ level, Figs. 3 and 4. To develop new boundary concentrations, the CMAQ hemispheric layer structure was processed to 14 layers and the median CMAQ hemispheric oxidized fraction of the gas phase $\mathrm{Hg}$, $\mathrm{Hg}^{2+} /\left(\mathrm{Hg}^{0}+\mathrm{Hg}^{2+}\right)$, was used to adjust GEOS-Chem $\mathrm{Hg}^{0}$ and $\mathrm{Hg}^{2+}$ concentrations to match the fraction in the oxidized phase while preserving the total gas phase $\mathrm{Hg}$ for the 14 vertical pressure levels. This adjustment was assumed to be constant in time and was applied to boundary concentrations derived from a 2002 GEOS-Chem model simulation for the January through February and July through August 2002 simulations. The total gaseous mercury at each pressure level in the GEOS-Chem boundary conditions was preserved, e.g. if CMAQ hemispheric runs estimated lower RGM concentrations the reduction in RGM in the GEOS-Chem boundary conditions was allocated to GEM. The GEOS-Chem PHg was not adjusted in these boundary conditions. These new boundary conditions agree better with the profiles measured by Schwarzendruber et al. (2009) below the $800 \mathrm{mb}$ pressure level and are lower than the observations above that, Fig. 3.

The statistical measures presented for these simulations in Table 3 show a mixed response to the change in boundary conditions. For both the January-February and JulyAugust periods, the $r^{2}$ values are slightly better using the adjusted boundary conditions ( 0.584 vs. 0.520 for JanuaryFebruary and 0.598 vs. 0.587 for July-August). For the JulAug period, all other measures favor the unadjusted boundary conditions (e.g., normalized mean bias of -0.23 using the unadjusted boundary conditions vs. -0.47 using the adjusted boundary conditions). For the January-February period, however, the statistical measures favor the adjusted boundary conditions (e.g., normalized mean bias of 0.31 using the unadjusted boundary conditions vs. -0.25 using the adjusted boundary conditions).

The changes in boundary concentrations are illustrated in Fig. 4. CMAQ simulations for January, February, July and August 2002 were made. The CMAQ simulations were run at $36 \mathrm{~km}$ horizontal grid resolution on a contiguous US domain. The simulated dry and wet deposition results for February 2002 are presented in Fig. 5. The sensitivity of wet deposition and dry deposition is nearly proportional to the reduction of $\mathrm{Hg}^{2+}$ in the boundary conditions at the 800 to $500 \mathrm{mb}$ pressure levels $(-48 \%$ and $-40 \%$ in January and February and $-38 \%$ and $-29 \%$ in July and August, respectively).

The effect of using the lower (adjusted) boundary conditions is apparent in both the simulated dry and wet deposition of mercury. Simulated dry deposition of mercury is substantially lower using the adjusted boundary conditions throughout the modeling domain, particularly in the SW US and northern portion of the domain where reductions in dry deposition are greater than $50 \%$. Simulated wet deposition is also lower using the adjusted boundary conditions. The relative reduction in wet deposition is largest $(\sim 50 \%)$ in the SW US, but the absolute change is small $\left(\sim 0.5 \mu \mathrm{g} \mathrm{m}^{-2}\right.$ month $\left.^{-1}\right)$ due to lower precipitation rates. The comparisons in Fig. 5 show the strong influence of boundary concentrations on the mercury deposition simulated by CMAQ.

\section{Alternate meteorology}

In this section, comparisons are made between the July 2001 and July 2005 simulations. Using an alternate set of meteorological inputs while maintaining other inputs constant shows that the response of the CMAQ simulation to changes in the boundary concentrations is also considerable using inputs other than the 2001 meteorology. The CMAQ simulations for July 2005 were made with meteorological input files also derived from MM5 outputs. Boundary conditions and emissions were the same as those in the 2001 simulations. As with the 2001 CMAQ simulations, two sets of simulations were made, one with boundary conditions based on the 


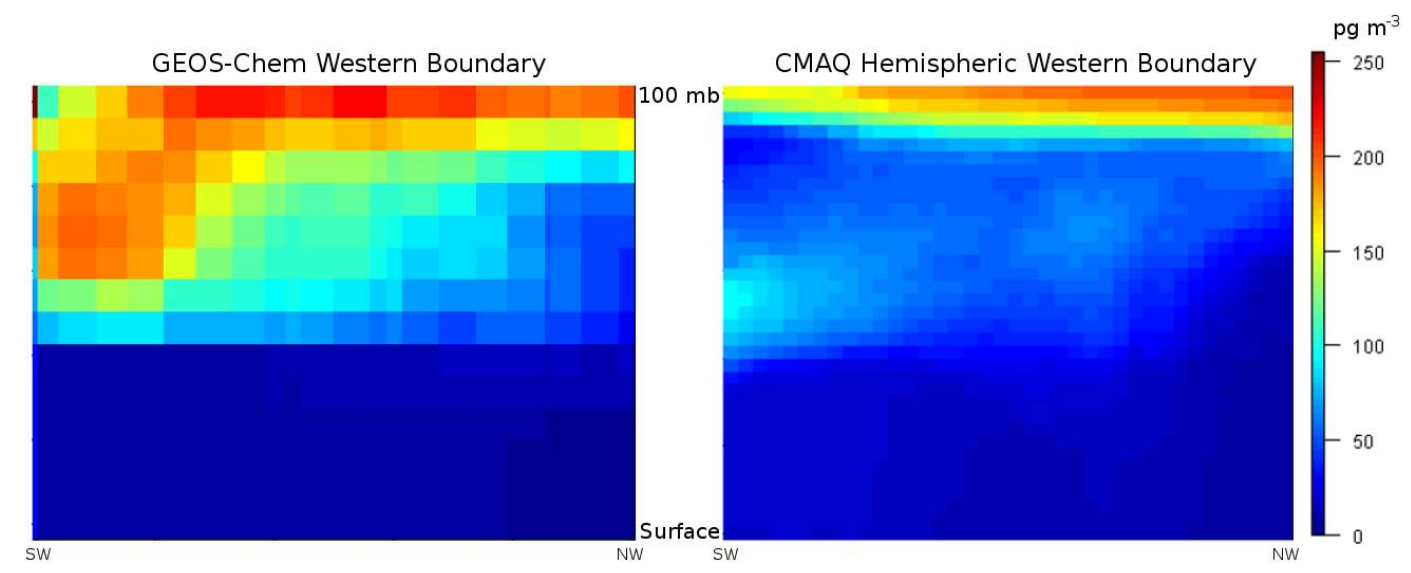

Fig. 4. $\mathrm{Hg}^{2+}$ western boundary conditions from the GEOS-Chem and CMAQ hemispheric simulations for April 2005.

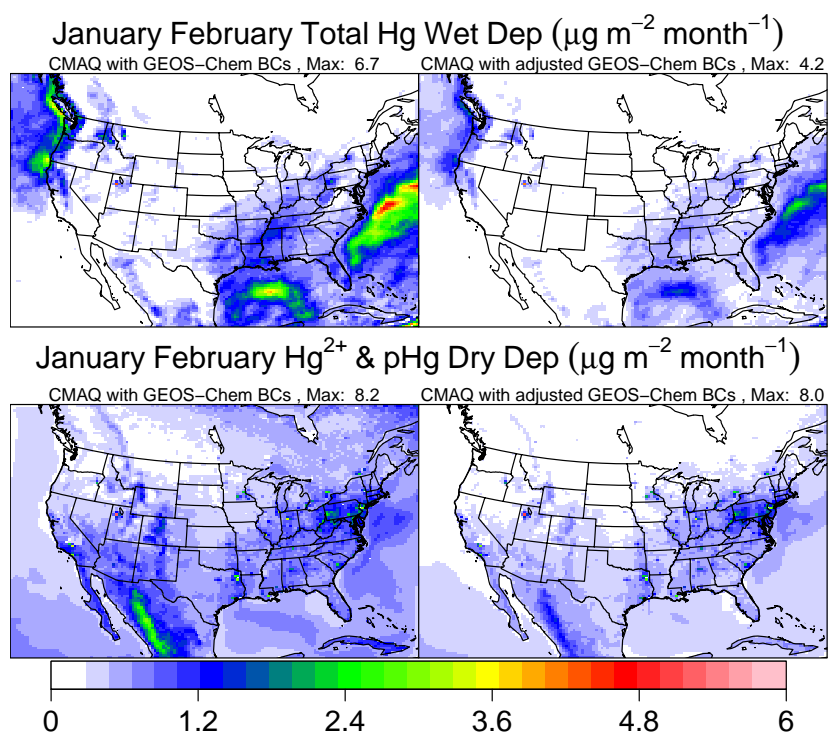

Fig. 5a. Comparison of simulated dry and wet mercury deposition for January-February 2002 from CMAQ runs using original GEOSChem based boundary conditions and adjusted boundary conditions. Circles on wet deposition plots indicate locations of Mercury Deposition Network wet deposition observations. Dry deposition includes only divalent forms of mercury.

GEOS-Chem global model and the other with boundary conditions based on the GRAHM global model.

Statistical performance measures for the July 2005 simulations using the GEOS-Chem and GRAHM derived boundary conditions are presented in Table 3 . The simulated mean wet deposition is lower than observed using either GEOS-Chem or GRAHM boundary conditions. The case using GRAHM is somewhat closer than the GEOS-Chem case, as was the case for the July 2001 simulations. Other statistical measures are slightly in favor of the GRAHM case, the most notable being an $r^{2}$ of 0.152 for the GRAHM case compared to 0.040 for the GEOS-Chem case. Data was again unavailable for a site

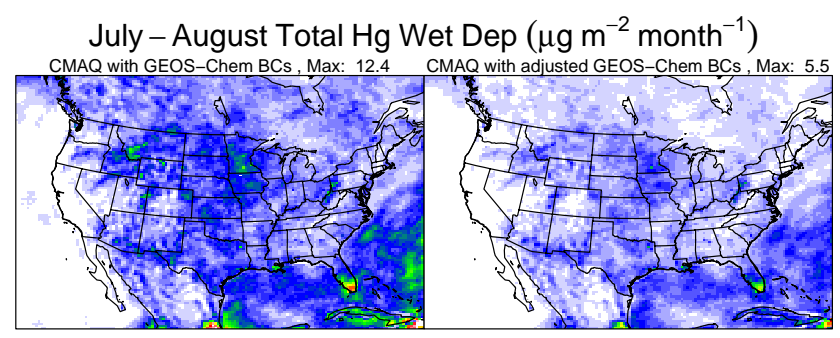

July-August $\mathrm{Hg}^{2+} \& \mathrm{pHg}$ Dry Dep $\left(\mu \mathrm{g} \mathrm{m}^{-2} \mathrm{month}^{-1}\right)$

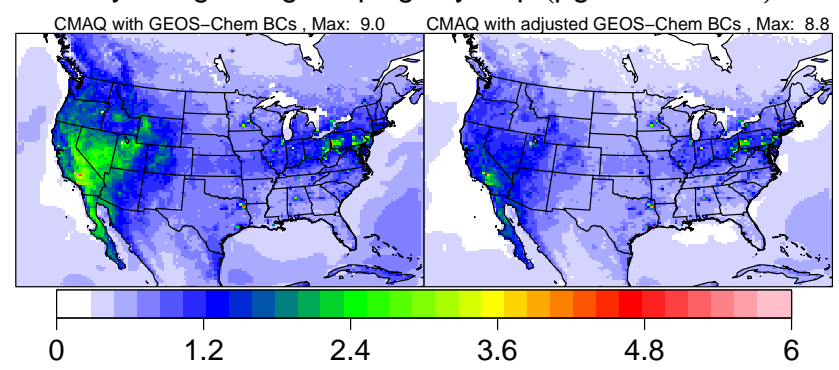

Fig. 5b. Comparison of simulated dry and wet deposition for JulyAugust 2002 from CMAQ runs using original GEOS-Chem based boundary conditions and adjusted boundary conditions. Circles on wet deposition plots indicate locations of Mercury Deposition Network wet deposition observations. Dry deposition includes only divalent forms of mercury.

in Arizona during this simulated period. Sites in California reported zero wet deposition for July 2005.

The wet and dry deposition of divalent mercury simulated by CMAQ for the July 2005 time period using the GEOSChem and GRAHM derived boundary conditions are shown in Fig. 6. The simulated dry deposition of mercury using the July 2005 meteorological files was 50 to $100 \%$ higher in the SW US than the simulated dry deposition of mercury using the July 2001 meteorological files, with a greater difference when the GEOS-Chem boundary conditions were used (compare to Fig. 2). Simulated wet deposition of mercury shows large spatial variations between the two simulations 

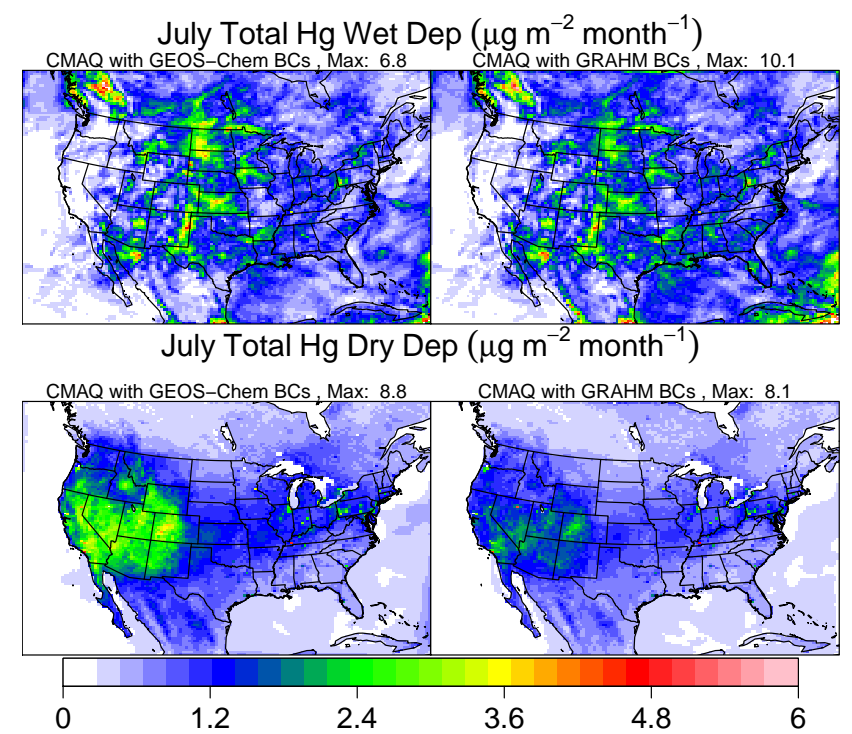

Fig. 6. Simulated mercury deposition from CMAQ runs using boundary conditions derived from GEOS-Chem and GRAHM global model simulations using 2005 meteorology.

using different meteorological inputs since wet deposition is driven by the presence of rainfall. The response of the model to the use of different boundary concentrations is similar using the 2005 meteorology to the response using the 2001 meteorology. Dry deposition of mercury in the SW US is $50 \%$ lower using the GRAHM based boundary conditions regardless of whether 2001 or 2005 meteorology was used. The response in simulated dry deposition of mercury is more pronounced using the 2005 meteorology than the 2001 meteorology. Although peak simulated wet deposition of mercury may be higher or lower using either set of boundary conditions, in general the wet deposition of mercury is lower over the contiguous US using the GRAHM boundary conditions compared to GEOS-Chem boundary conditions. This is most noticeable in the Southeast (SE) US where simulated wet deposition is lower by about $50 \%$ using the GRAHM boundary conditions compared to using the GEOS-Chem boundary conditions, while in the SW US the difference is consistently less than $50 \%$.

\section{Effect of high altitude mercury boundary concentrations}

In order to assess the effects of the high altitude boundary concentrations on mercury deposition, boundary concentrations of all mercury species were zeroed out in the top two layers (i.e. layers 13 and 14) which corresponds to a height of approximately $5400 \mathrm{~m}$ and above. These simulations were made with the GEOS-Chem boundary conditions using both the 2001 and 2005 meteorology.
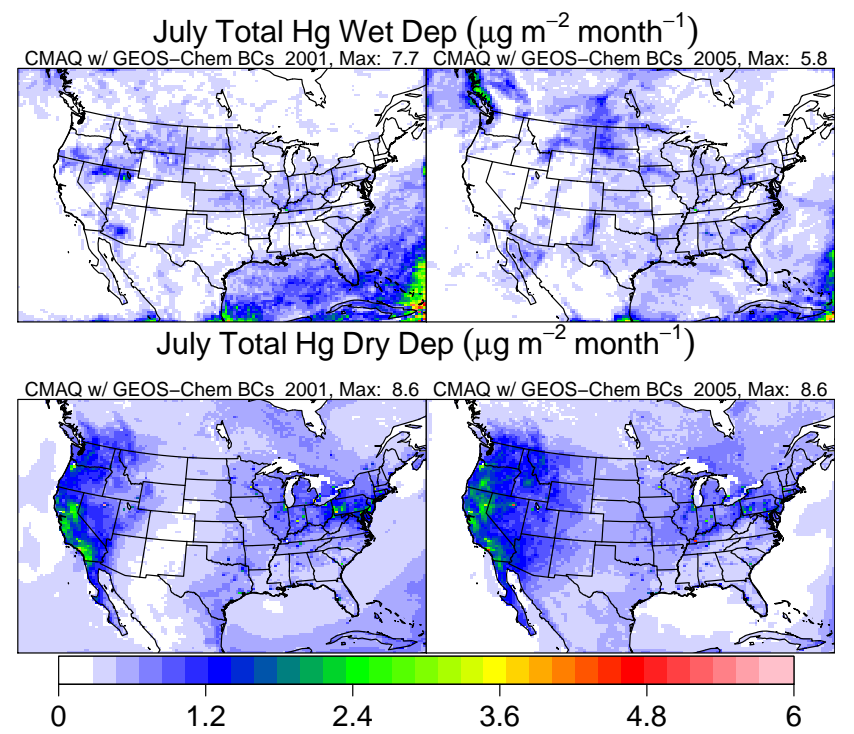

Fig. 7. Simulated mercury deposition from CMAQ runs using boundary conditions derived from a GEOS-Chem simulation with the upper layer mercury concentrations zeroed out using 2001 and 2005 meteorology.

The simulated deposition in Fig. 7 can be compared directly to Figs. 2 and 6. Note that both wet deposition and dry deposition are reduced in both meteorological years. In the SW US, the model estimates substantially lower deposition of mercury when the upper layers of the boundary concentrations are set to zero for all mercury species. To see the influence of the upper layer mercury on deposition more clearly, the differences between the simulations with and without the upper layer mercury boundary conditions were calculated and expressed as a percent contribution from the upper layer boundary conditions to deposition (Fig. 8).The strong influence of the higher altitude mercury boundary concentrations on the simulated deposition of mercury is clear from this figure. From 20 to $80 \%$ of the simulated dry deposition of mercury in the SW US originated from the upper layers of the boundary conditions. The influence of the upper layer boundary conditions on simulated wet deposition of mercury is even greater than for dry deposition. Over most of the SW US, more than $80 \%$ of the simulated wet deposition of mercury originates from the upper layer boundary conditions. Unlike other species that typically have low concentrations at higher altitude, relatively high concentrations of mercury at higher altitudes must be considered when setting boundary concentrations for CMAQ model simulations. Since these estimates of influence of upper level boundary concentrations are derived using exclusively the CMAQ model and its associated databases, studies using different models or observational techniques could come to different conclusions. 

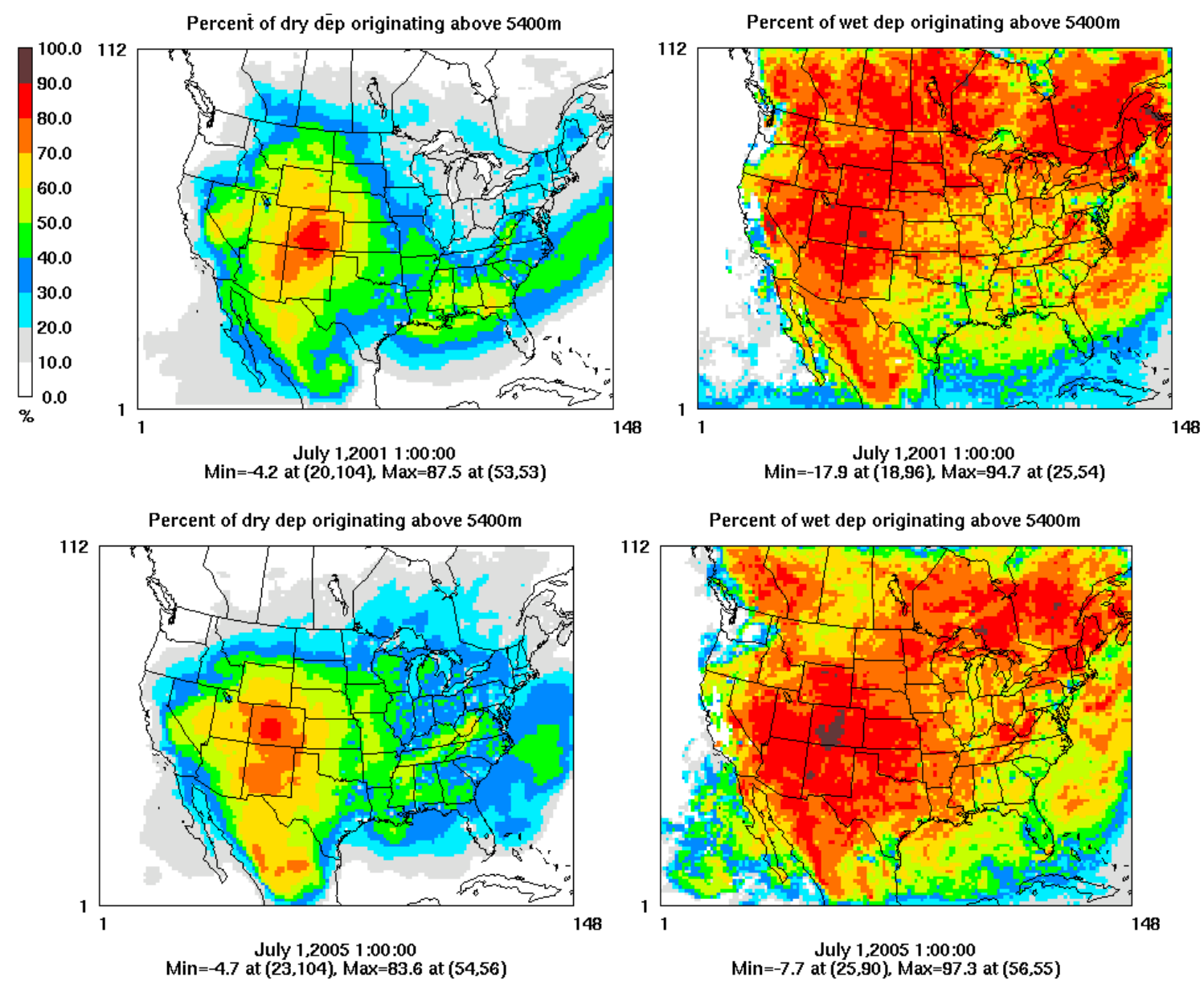

Fig. 8. Simulated percent contribution of mercury originating from boundary concentrations above $5400 \mathrm{~m}$ for dry and wet mercury deposition using both 2001 and 2005 meteorology.

\section{Tracers showing upper tropospheric impact on surface concentrations}

In order to assess whether the contributions of high altitude boundary concentrations to mercury deposition are primarily due to high mercury levels in the upper atmosphere or transport from the upper layers to lower layers, simulations were conducted with unit concentration tracers along each of the domain boundaries, broken down by model layer. These simulations were conducted for the month of July using both 2001 and 2005 meteorology.

Preparation of the tracer simulations involved a minor modification to the CMAQ 4.7.1 code and preparation of initial and boundary concentration files that included tracer concentrations. The CMAQ "trac0" header files, such as "TR_SPC.EXT", are supplied in the release version of the model with zero tracers. These files were modified to include 26 tracers with names such as "TRAC1", "TRAC2", and so forth. These tracers were assigned to boundaries, initial concentrations and layers as shown in Table 4. For example, therefore, "TRAC12" was assigned unit concentration in layers 3 through 6 on the north boundary, and zero concentration elsewhere, including in the initial concentration file.

The spatial pattern of the contributions of the upper layers to surface layer is similar for both sets of meteorological inputs (see Fig. 9), although the peak contribution from the upper layers is higher using the 2005 meteorology. The greater simulated dry deposition of mercury using the 2005 meteorology appears to be at least in part a result of greater influence of the upper layer boundaries on the surface layer. The spatial patterns suggest, and the conclusion is confirmed by examining animations of tracer concentrations, that the largest contribution to the lower layers from the upper layers occurs over the Rocky Mountains, which then spreads out to influence other parts of the domain.

At two locations in the domain, one in Arizona (grid cell $(44,45))$ and one in California (grid cell $(24,51)$ ), the influence of the upper layer boundaries was examined in more detail. These locations were chosen to represent areas in the SW US that are strongly impacted by upper layer boundary conditions of mercury. The green symbols in Fig. 10 show the locations subject to this more detailed examination. A 
Table 4. Definition of tracers used in tracer simulations.

\begin{tabular}{llll}
\hline Tracer Name & Boundary & \multicolumn{2}{l}{ Layers represented } \\
\hline TRAC1 & West & Layers & $1-2$ \\
TRAC2 & West & Layers & $3-6$ \\
TRAC3 & West & Layer & 7 \\
TRAC4 & West & Layer & 8 \\
TRAC5 & West & Layer & 9 \\
TRAC6 & West & Layer & 10 \\
TRAC7 & West & Layer & 11 \\
TRAC8 & West & Layer & 12 \\
TRAC9 & West & Layer & 13 \\
TRAC10 & West & Layer & 14 \\
\hline TRAC11 & North & Layers & $1-2$ \\
TRAC12 & North & Layers & $3-6$ \\
TRAC13 & North & Layer & 7 \\
TRAC14 & North & Layer & 8 \\
TRAC15 & North & Layer & 9 \\
TRAC16 & North & Layer & 10 \\
TRAC17 & North & Layer & 11 \\
TRAC18 & North & Layer & 12 \\
TRAC19 & North & Layer & 13 \\
TRAC20 & North & Layer & 14 \\
TRAC21 & East & Layer & $1-12$ \\
TRAC22 & East & Layer & $13-14$ \\
\hline TRAC23 & South & Layer & $1-12$ \\
TRAC24 & South & Layer & $13-14$ \\
\hline TRAC25 & ICs & Layer & $1-12$ \\
TRAC26 & ICs & Layer & $13-14$ \\
\hline & & & \\
\hline & & & 14 \\
& & & 14 \\
\hline
\end{tabular}

breakdown of contributors to surface tracer concentrations is shown in Fig. 11. The influence of the upper boundaries on the surface is almost $50 \%$ at the Arizona location, but is only about $30 \%$ at the California location. The influence of the upper layers comes not only from the western boundary, but also from other boundaries as well. In particular, a further breakdown shows that there is a strong influence from the south boundary. Conversely, the 2001 meteorological case shows a relatively small influence of the lower part of the western boundary at the Arizona location, although the upper part of the western boundary has a fairly large influence. These results could be due to different flow fields from the meteorology in these model simulations.

\section{Tracers with increased vertical resolution impact on surface concentrations}

The 14-layer simulations presented thus far include relatively limited vertical resolution in the upper layers. It is therefore of interest to determine if the influences of the upper layers may be exaggerated in the simulations due to this low resolution. An additional simulation was therefore conducted using meteorological files based on the same MM5 model runs for
2001 used for the tracer simulation in the previous section. The MM5 model runs used 34-layers. For the prior runs, the CMAQ ready meteorological files were processed to 14 layers, requiring degradation in vertical resolution, although the vertical extent of the MM5 domain was maintained. In this simulation, the CMAQ ready meteorological files retained all 34 layers of the MM5 output so the resolution was not degraded.

Tracers were defined in a manner similar to the methodology described for the 14-layer tracer simulation in Sect. 6. In this case, 52 tracers were used and covered the 34 layers included in this domain.

Using higher resolution meteorological files does not change the basic conclusions about the strong influence of upper layer boundaries on simulated surface layer mercury concentrations. The area of the domain affected by upper layers is similar using either 14 or 34 layers (see Figs. 9a and 12). The peak influence of the upper layer boundaries is somewhat higher for the tracer concentration using the 34 layer meteorological files. The breakdown of the influence of the boundaries at the locations in Arizona and California (Fig. 11) shows similar influence from the upper boundaries overall to what is shown for 2001. The relative influence of west vs. other boundaries differs, however, depending on whether the 14 or 34 layer files are used.

\section{Conclusions}

CMAQ dry deposition in the SW US is sensitive to differences in the atmospheric dynamics and atmospheric mercury chemistry parameterizations of the global models used for boundary conditions. Changes in estimates of boundary concentrations affect conclusions about the total amount of mercury deposition. This implies a large uncertainty in what is referred to as background mercury. The contribution from upper layers to wet and dry deposition is large based on sensitivity simulations using GEOS-Chem boundary concentrations. Tracer simulations imply that the high contribution from these upper layers is a result of the large amount of transport of material from the upper layers to the surface. It can therefore be expected that any boundary concentrations which include significant mass of divalent mercury in the upper layers will also result in a large influence of the upper layer boundary concentrations on mercury deposition. The magnitude of the boundary concentrations throughout the depth of the modeling domain must be carefully considered given these sensitivities, not just within the boundary layer or mixed layer. Although the details of simulated deposition change with different meteorological years, the strong influence of the boundaries is present in all cases investigated, and the response to changes in boundary concentrations is similar. Localized mixing brings upper-level material to the surface. The influence of mercury from the upper layers spreads throughout most of the US. In some 
(a) 2001 Meteorology

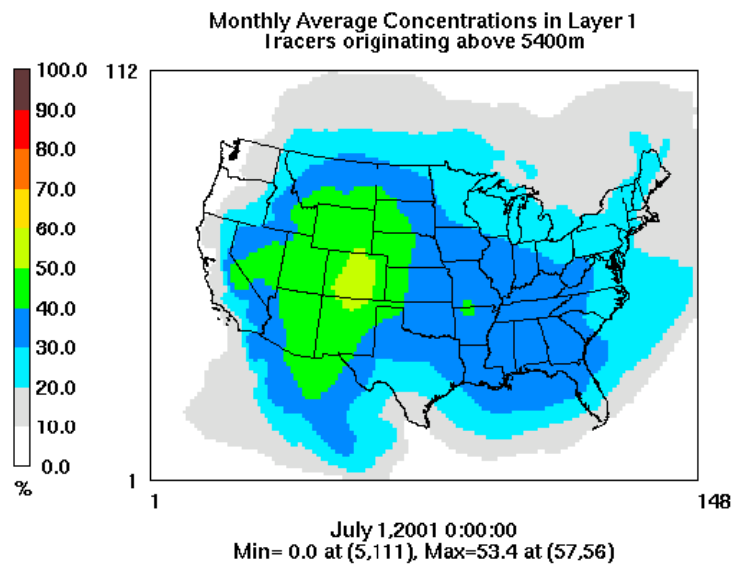

(b) 2005 Meteorology

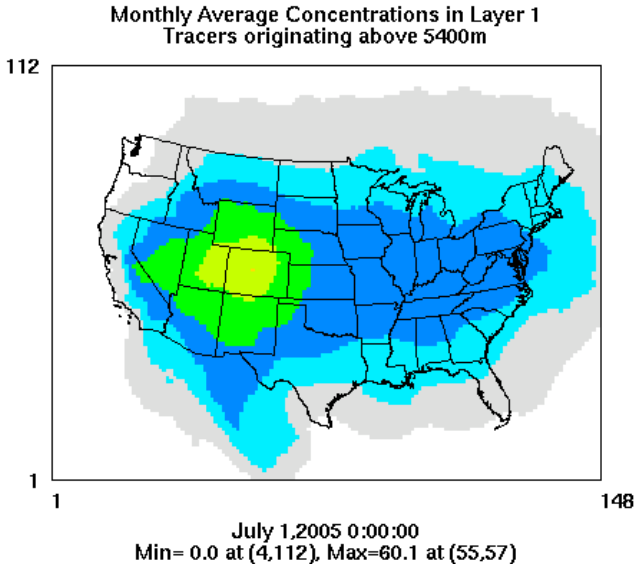

Fig. 9. Percent contribution of tracers originating above $5400 \mathrm{~m}$ to the surface layer concentrations using 2001 and 2005 meteorological files. Contributions are based on monthly averages of tracer concentrations.

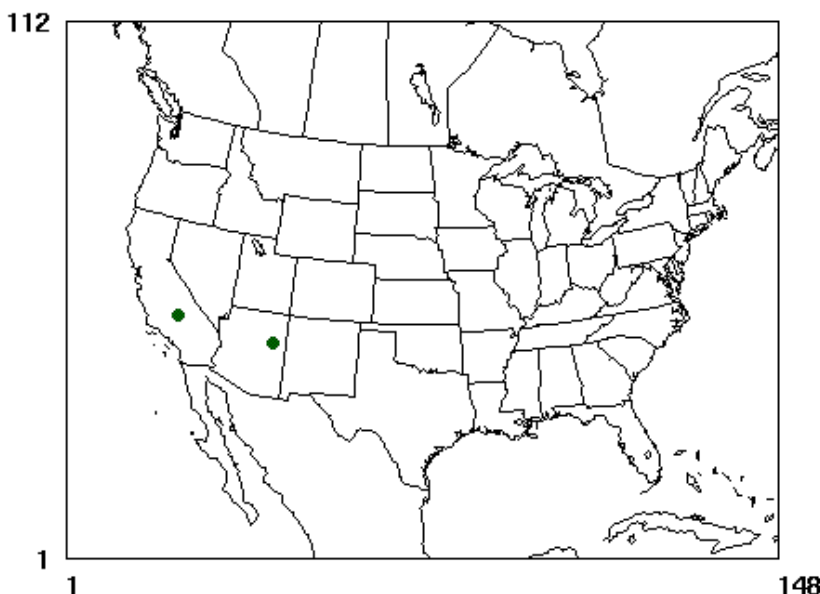

Fig. 10. Locations in Arizona and California examined in detail Fig. 11.

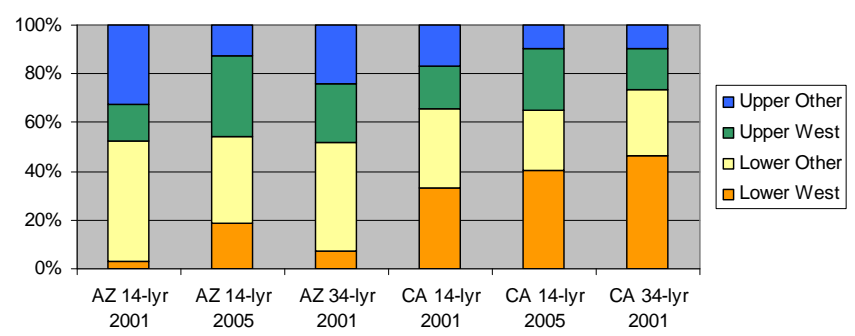

Fig. 11. Relative contributions of tracers to surface layer concentrations. "Upper" refers to tracers originating above $5400 \mathrm{~m}$; "lower" refers to tracers originating below $5400 \mathrm{~m}$. "West" includes only tracers on the western boundary of the domain. "Other" includes contributions from all other boundaries and initial concentrations. The fractions presented are based on monthly averages of tracer concentrations.

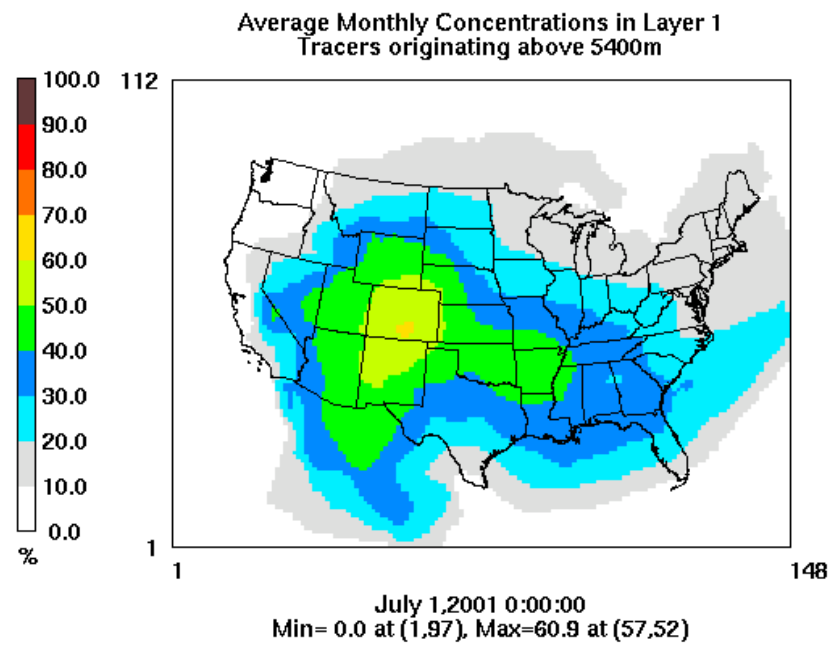

Fig. 12. Percent contribution of tracers originating above $5400 \mathrm{~m}$ to surface layer air mass, using 2001 meteorological inputs with 34 vertical layers. Contributions are based on monthly averages of tracer concentrations.

cases (e.g., western boundary air mass at Arizona site on July 10), mixing appears to exchange the upper-level air mass with the lower-level air mass. The influence of the upper layer boundary conditions is not restricted to the western boundary; boundary conditions from upper layers along other boundaries can also have a strong influence at locations in the SW US. The upper layer boundary conditions influence both wet and dry deposition (e.g., over $80 \%$ of the simulated wet deposition in the SW originated from the upper layers of the boundary conditions). The model indicates that the area that experiences the greatest amount of upper tropospheric transport of mercury to the surface is in the Rocky Mountains and that this influences other parts of the 
domain. Elevated levels of $\mathrm{Hg}^{2+}$ have been observed at high altitude monitoring sites and attributed to deep tropospheric mixing (Faïn et al., 2009) in agreement with these modeled results. Increasing the vertical resolution of the input fields used for the CMAQ modeling does not reduce the influence of the upper layer boundary concentrations on the surface air mass in the SW US, although the simulation of the tracers is altered somewhat by the use of higher vertical resolution. The influence of boundary concentrations of $\mathrm{Hg}$ on ambient surface concentrations and subsequently dry deposition from $\mathrm{Hg}$ in the free troposphere in CMAQ is in agreement with the measurements of Lyman and Gustin (2009) and WeissPenzias et al. (2009) and with the modeling results of Amos et al. (2012). If free tropospheric $\mathrm{Hg}$ (II) concentrations were too high in the boundary conditions, the entrainment of this air in the model might partially explain the recently documented discrepancies between modeled and observed speciated mercury concentrations at the surface (Baker and Bash, 2012).

\section{Supplementary material related to this article is available online at: http://www.atmos-chem-phys.net/13/ 997/2013/acp-13-997-2013-supplement.zip.}

Acknowledgements. Financial support for the modeling conducted in this study was provided by the Office of Water, US Environmental Protection Agency and by the National Exposure Research Laboratory, US Environmental Protection Agency.

Disclaimer. Although this work was reviewed by EPA and approved for publication, it may not necessarily reflect official Agency policy.

Edited by: A. Dastoor

\section{References}

Amos, H. M., Jacob, D. J., Holmes, C. D., Fisher, J. A., Wang, Q., Yantosca, R. M., Corbitt, E. S., Galarneau, E., Rutter, A. P., Gustin, M. S., Steffen, A., Schauer, J. J., Graydon, J. A., Louis, V. L. St., Talbot, R. W., Edgerton, E. S., Zhang, Y., and Sunderland, E. M.: Gas-particle partitioning of atmospheric $\mathrm{Hg}(\mathrm{II})$ and its effect on global mercury deposition, Atmos. Chem. Phys., 12, 591-603, doi:10.5194/acp-12-591-2012, 2012.

Ariya, P., Dastoor, A., Amyot, M., Schroeder, W., Barrie, L., Anlauf, K., Raofie, F., Ryzhkov, A., Davignon, D., Lalonde, J., and Steffen, A.: Arctic: A sink for mercury, Tellus, 56B, 397-403, 2004.

Baker, K. and Bash, J.: Regional scale photochemical model evaluation of total mercury wet deposition and speciated ambient mercury, Atmos. Environ., 49, 151-162, 2012.

Bash, J. O.: Description and initial simulation of a dynamic bidirectional air-surface exchange model for mercury in Community Multiscale Air Quality (CMAQ) model, J. Geophys. Res., 115, D06305, doi:10.1029/2009JD012834, 2010.
Bey, I., Jacob, D., Yantosca, R., Logan, J., Field, D., Fiore, A., Li, Q., Liu, H., Mickley, L., and Schultz, M.: Global modeling of tropospheric chemistry with assimilated meteorology: Model description and evaluation, J. Geophys. Res., 106, 23073-23095, 2001.

Bullock Jr., O. and Brehme, K. A.: Atmospheric mercury simulation using the CMAQ model: Formulation description and analysis of wet deposition results, Atmos. Environ., 36, 2135-2146, 2002.

Bullock Jr., O., Atkinson, D., Braverman, T., Civerolo, K., Dastoor, A., Davignon, D., Ku, J., Lohman, K., Myers, T., Park, R., Seigneur, C., Selin, N., Sistla, G., and Vijayaraghavan, K.: The North American Mercury Model Intercomparison Study (NAMMIS): Study description and model-to-model comparisons, J. Geophys. Res., 113, D17310, doi:10.1029/2008JD009803, 2008.

Bullock Jr., O., Atkinson, D., Braverman, T., Civerolo, K., Dastoor, A., Davignon, D., Ku, J.-Y., Lohman, K., Myers, T., Park, R., Seigneur, C., Selin, N., Sistla, G., and Vijayaraghavan, K.: An Analysis of Simulated Wet Deposition of Mercury from the North American Mercury Model Intercomparison Study (NAMMIS), J. Geophys. Res., 114, D08301, doi:10.1029/2008JD011224, 2009.

Dastoor, A. and Larocque, Y.: Global circulation of atmospheric mercury: A modeling study, Atmos. Environ., 38, 147-161, 2004.

EPA: Technical support document for the final Clean Air Mercury Rule: Air quality modeling, EPA Office of Air Quality Planning and Standards, Research Triangle Park, North Carolina, available at: http://www.epa.gov/ttn/atw/utility/aqm oar-2002-0056-6130.pdf, 2005a.

EPA: Emissions Inventory and Emissions Processing for the Clean Air Mercury Rule (CAMR), EPA OAQPS, available at: http: //www.epa.gov/ttn/atw/utility/emiss_inv_oar-2002-0056-6129. pdf, 2005b.

EPA: Meteorological Modeling Performance Evaluation for the Annual 2005 Continental US 36-km Domain Simulation, EPA Office of Air Quality Planning and Standards (OAQPS), 2009.

Faïn, X., Obrist, D., Hallar, A. G., Mccubbin, I., and Rahn, T.: High levels of reactive gaseous mercury observed at a high elevation research laboratory in the Rocky Mountains, Atmos. Chem. Phys., 9, 8049-8060, doi:10.5194/acp-9-8049-2009, 2009.

Foley, K. M., Roselle, S. J., Appel, K. W., Bhave, P. V., Pleim, J. E., Otte, T. L., Mathur, R., Sarwar, G., Young, J. O., Gilliam, R. C., Nolte, C. G., Kelly, J. T., Gilliland, A. B., and Bash, J. O.: Incremental testing of the Community Multiscale Air Quality (CMAQ) modeling system version 4.7, Geosci. Model Dev., 3, 205-226, doi:10.5194/gmd-3-205-2010, 2010.

Grell, G., Dudhia, A., and Stauffer, D.: A description of the FifthGeneration PennState/NCAR Mesoscale Model (MM5), NCAR Technical Note NCAR/TN-398+STR, available at: http://www. mmm.ucar.edu/mm5/doc1.html, 1994.

Hynes, A. J., Donohoue, D. L., Goodsite, M. E., and Hedgecock, I. M.: Our current understanding of major chemical and physical processes affectinf mercury dynamics in the atmosphere and at the air-water/terrestrial interfaces, in: Mercury Fate and Transport in the Global Atmosphere, editd by: Pirrone, N. and Mason, R., Springer, New York, 427-457, 2009.

Lyman, S. and Gustin, M. S.: Determinants of Atmospheric Mercury Concentrations in Reno, Nevada, USA, Sci. Total. Environ., 408, 431-438, 2009. 
Otte, T., Pouliot, G., Pleim, J., Young, J., Schere, K., Wong, D., Lee, P., Tsidulko, M., McQueen, J., Davidson, P., Mathur, R., Chuang, H., DiMego, G., and Seaman, N.: Linking the Eta model with the Community Multiscale Air Quality (CMAQ) modeling system to build a national air quality forecasting system, Weather Forecast., 20, 367-384, 2005.

Pongprueksa, P., Lin, C. J., Lindberg, S. E., Jang, C., Braverman, T., Bullock, O. R., Ho, T. C., and Chu, H. W.: Scientific uncertainties in atmospheric mercury models III: Boundary and initial conditions, model grid resolution, and $\mathrm{Hg}$ (II) reduction mechanism, Atmos. Environ., 42, 1828-1845, 2008.

Schere, K., Flemming, J., Vautard, R., Chemel, C., Colette, A., Hogrefe, C., Bessagnet, B., Meleux, F., Mathur, R., Roselle, S., $\mathrm{Hu}, \mathrm{R} .$, Sokhi, R., Rao, S., and Galmarini, S.: Trace gas/aerosol boundary concentrations and their impacts on continental-scale AQMEII modeling domains, Atmos. Environ., 53, 38-50, 2011.

Selin, N., Jacob, D., Park, R., Yantosca, R., Strode, S., Jaegle, L., and Jaffe, D.: Chemical cycling and deposition of atmospheric mercury: Global constraints from observations, J. Geophys. Res., 112, D02308, doi:10.1029/2006JD007450, 2007.
Sommar, J., Hallquist, M., Ljungström, and Lindqvist, O.: On the gas phase reactions between volatile biogenic mercury species and the nitrate radical, J. Atmos. Chem., 27, 233-247, 1997.

Subir, M., Ariya, P. A., and Dastoor, A. P.: A review of uncertainties in atmospheric modeling of mercury chemistry I. Uncertainties in existing kinetic parameters - Fundamental limitations and the importance of heterogeneous chemistry, Atmos. Environ., 45, 5664-5676, 2011.

Swartzendruber, P., Jaffe, D., and Finley, B.: Development and first results of an aircraft-based, high time resolution technique for gaseous elemental and reactive (oxidized) gaseous mercury, Environ. Sci. Technol., 43, 7484-7489, 2009.

Vermette, S., Lindberg, S., and Bloom, N.: Field Tests for a Regional Mercury Deposition Network - Sampling Design and preliminary Test Results, Atmos. Environ., 29, 1247-1251, 1995.

Weiss-Penzias, S., Gustin, M. S., and Lyman, S. N.: Observations of speciated atmospheric mercury at three sites in Nevada, USA: evidence for a free tropospheric source of reactive gaseous mercury, J. Geophys. Res., 114, D14302, doi:10.1029/2008JD011607, 2009. 